
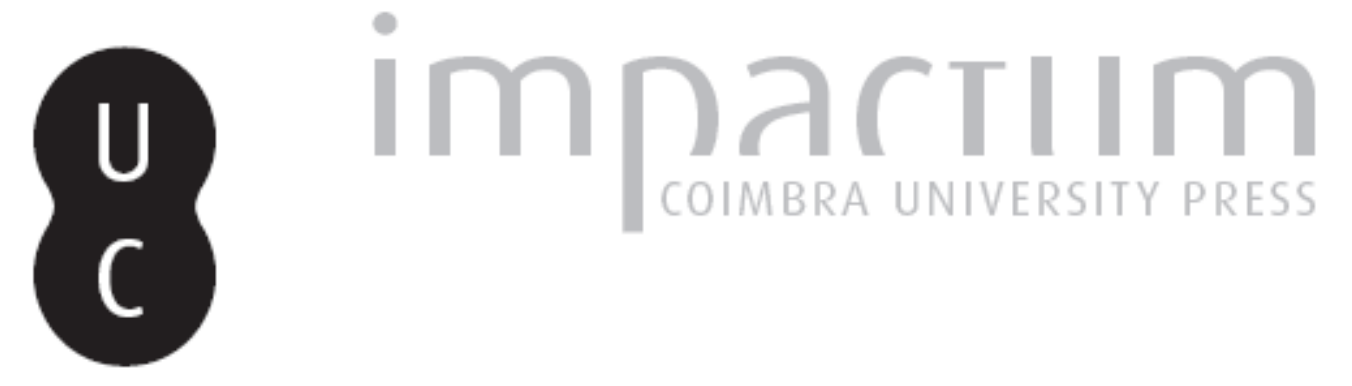

O amuleto cordiforme na Arte Egípcia: as representações humanas

Autor(es): $\quad$ Sousa, Rogério Ferreira de

Publicado por: Centro de História da Universidade de Lisboa

URL persistente:

URI:http://hdl.handle.net/10316.2/23833

DOI:

DOI:http://dx.doi.org/10.14195/0871-9527_18_5

Accessed : $\quad$ 26-Apr-2023 10:42:09

A navegação consulta e descarregamento dos títulos inseridos nas Bibliotecas Digitais UC Digitalis, UC Pombalina e UC Impactum, pressupõem a aceitação plena e sem reservas dos Termos e Condições de Uso destas Bibliotecas Digitais, disponíveis em https://digitalis.uc.pt/pt-pt/termos.

Conforme exposto nos referidos Termos e Condições de Uso, o descarregamento de títulos de acesso restrito requer uma licença válida de autorização devendo o utilizador aceder ao(s) documento(s) a partir de um endereço de IP da instituição detentora da supramencionada licença.

Ao utilizador é apenas permitido o descarregamento para uso pessoal, pelo que o emprego do(s) título(s) descarregado(s) para outro fim, designadamente comercial, carece de autorização do respetivo autor ou editor da obra.

Na medida em que todas as obras da UC Digitalis se encontram protegidas pelo Código do Direito de Autor e Direitos Conexos e demais legislação aplicável, toda a cópia, parcial ou total, deste documento, nos casos em que é legalmente admitida, deverá conter ou fazer-se acompanhar por este aviso. 



Revista de História Antiga

\author{
Centro de História \\ da Universidade de Lisboa
}

18

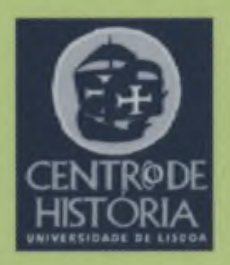

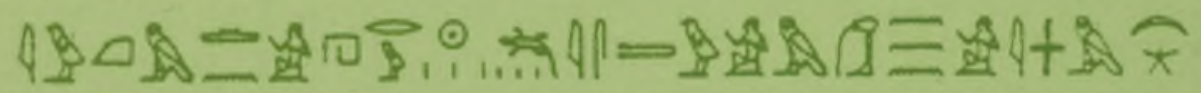

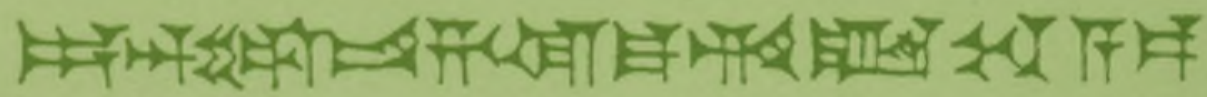

MHNIN AEI $\Delta$ E $\Theta E A ~ \Pi H \Lambda H I A \triangle E \Omega$ 


\title{
O AMULETO CORDIFORME NA ARTE EGÍPCIA: AS REPRESENTAÇÕES HUMANAS
}

\author{
ROGÉRIO FERREIRA DE SOUSA \\ Instituto Superior de Ciências da Saúde - Norte \\ solar.benu@gmail.com
}

\section{Resumo}

Apesar do amuleto cordiforme ser um dos objectos de protecção mágica mais importante no Antigo Egipto, pouca atenção tem sido dada ao estudo do seu simbolismo. $\mathrm{O}$ amuleto cordiforme foi um dos amuletos mais frequentemente representados na arte egípcia, sendo frequentemente usado como atributo iconográfico de deuses e humanos. Apresentamos neste artigo os principais contextos pictóricos em o amuleto cordiforme é usado por seres humanos de modo a evidenciar a seu significado ritual.

\section{Abstract}

Notwithstanding the fact that the heart amulet stands amongst the most important items of magical protection in Ancient Egypt, little attention has been dedicated to the study of its symbolism. The heart amulet was perhaps one of the most frequently depicted amulets in Egyptian Art, being a common iconographic feature in some well defined pictorial contexts where it appears as a distinctive attribute of gods or humans. We present in this article the main pictorial contexts where the heart amuletis used by human beings, trying to point out its ritual meaning. 
Apresentámos no número 15 da revista Cadmo um artigo dedicado ao estudo formal do amuleto do coração(1), uma categoria de objectos apotropaicos que, embora apresente uma notável complexidade simbólica, nunca foi estudada de um modo sistemático. Michel Malaise abordou a questão num artigo que publicou em $1975^{(2)}$ mas, como o próprio autor reconheceu, apenas inventariou algumas ocorrências que registou ao longo da recolha que desenvolveu para o seu estudo de referência sobre os escaravelhos do coração(3). Devido certamente à sua importância simbólica e ritual, os amuletos do coração foram abundantemente representados na arte egípcia, circunstância essa que nos permite recolher informação preciosa para clarificar a função mágica destes objectos e melhor delimitar o seu significado simbólico. No estudo que dedicámos à simbólica do coração(4) tornou-se, por isso, fundamental, empreender o trabalho que Michel Malaise já havia apontado como necessário e promissor. $\mathrm{O}$ artigo que agora apresentamos alarga o estudo que desenvolvemos em torno da caracterização formal dos amuletos do coração através do inventário dos contextos de representação mais significativos destes amuletos. A magnitude deste objectivo leva-nos, por agora, apenas a abordar as representações relacionadas com o uso do amuleto por seres humanos, deixando para uma próxima publicação a tarefa de sistematizar os contextos de utilização do amuleto no âmbito das representações de divindades, onde o amuleto é também abundantemente representado.

Num estudo que se debruça sobre as representações de amuletos convém em primeiro lugar alertar para algumas dificuldades que, em alguns casos, são difíceis ou mesmo impossíveis de superar. Quando lidamos com as representações de um objecto, nem sempre temos a sorte de encontrar uma representação definida ou inteiramente inteligível, o que, num amuleto como o do coração, devido à sua simplicidade de formas, por vezes se pode traduzir numa deficiente identificação. Esta confusão com outros amuletos pode ser ilustrada na célebre estátua de calcário pintado do príncipe Rahotep (IV dinastia) que apresenta um amuleto que muitas vezes é identificado com o amuleto cordiforme ${ }^{(5)}$. A confusão entre este amuleto e o cordiforme deve-se ao contorno do objecto que apresenta projecções laterais semeIhantes às artérias laterais do amuleto cordiforme. No amuleto que representa a tartaruga, no entanto, estas projecções laterais (que representam as patas) são em número de quatro (duas em cada lado do objecto) ${ }^{(6)}$. Um outro amuleto que oferece problemas de interpretação é frequentemente encontrado nas estátuas de Senuseret III e de 
outros soberanos da XII dinastia(7). Este amuleto tem a forma de uma dupla concha atravessada, por vezes, por uma haste. Embora não se assemelhe nada à tradicional representação do amuleto cordiforme, a verdade é que certas representações da Época Baixa, ou de períodos posteriores, representam o coração de um modo semelhante, sob a configuração que denominámos de "amuleto semente de bordo descaído" ${ }^{(8)}$. A identificação deste tipo de amuletos não é certa mas, no caso das estátuas de Senuseret III e de outros soberanos do Império Médio, parece tratar-se de um invólucro que encerrava um objecto secreto ou bolas de incenso, como sugere a representação deste tipo de saquinhos nos frisos dos sarcófagos dessa mesma época. Estes são apenas alguns exemplos das dificuldades inerentes à correcta identificação do objecto efectivamente representado.

Infelizmente, as limitações de espaço não nos permitem fazer acompanhar o texto com as ilustrações que melhor possibilitariam ao leitor a compreensão das questões iconográficas aqui abordadas. De qualquer modo, para se inteirar sobre as representações aqui referidas, o leitor poderá consultar o catálogo que acompanha a nossa dissertação de doutoramento ${ }^{(9)}$.

\section{A representação do amuleto do coração em individualidades da realeza}

As representações reais com o amuleto cordiforme são raras. O mais antigo testemunho do uso de um amuleto cordiforme pela realeza egípcia remonta ao reinado de Ahmés, o fundador da XVIII dinastia, e está patente na famosa Estela da Doação, erguida em Karnak para comemorar a criação do cargo de esposa divina de $\operatorname{Amon}^{(10)}$. O príncipe herdeiro, que está representado entre o rei e a rainha, é denominado "o filho primogénito do rei» e é conduzido à presença de Amon-Ré. Como é habitual nas representações das crianças, o príncipe, o futuro rei Amen-hotep I, apresenta-se aqui completamente nu, com o amuleto cordiforme como único adereço. A associação do amuleto aos príncipes reais também está patente num grupo escultórico da XVIII dinastia, encontrado em Zagazig, que representa uma ama com quatro príncipes enfeitados com este amuleto(11).

Tutmés III é representado no templo funerário de Hatchepsut, em Deir el-Bahari, com uma versão muito elaborada do amuleto cordiforme ${ }^{(12)}$. Usurpando uma imagem de Hatchepsut, o soberano faz-se 
representar com um peitoral onde o coração, ladeado por serpentes sagradas, é encimado por um disco solar. A elaborada peça é usada pelo soberano no contexto da oferenda ritual dos produtos exóticos adquiridos através da expedição enviada a Punt, distante região situada a sul do mar Vermelho. Trata-se, portanto do culminar do ciclo de representações relacionadas com a expedição de Punt, que domina todo o programa decorativo da colunata meridional do segundo terraço. Ocupando toda a parede, esta cena final apresenta o rei diante da barca e do santuário de Amon. $\mathrm{O}$ amuleto aqui utilizado reflecte a grandeza do momento e concorria certamente para sublinhar a elevada mensagem divulgada pelos relevos: ao garantir o culto divino, o soberano, assegurava a função de intermediário com os deuses. O amuleto cordiforme parece, neste contexto, assinalar o estatuto divino do faraó que Ihe conferia legitimidade para assegurar o culto divino e, desse modo, garantir a presença dos deuses sobre a terra.

Uma outra representação real pertence à XIX dinastia e pode ser contemplada no templo cenotáfio de Seti I, em Abido, onde é o próprio Merenptah que usa o amuleto cordiforme ${ }^{(13)}$. $\mathrm{O}$ uso do amuleto tem, neste monumento, um cariz funerário e relaciona-se com a justificação do rei, uma vez que é utilizado no contexto da apresentação do faraó diante de Osíris. Estamos, portanto, perante um uso bem diferente das anteriores, onde o amuleto figura como um atributo ritual do príncipe ou do soberano.

Da XXV dinastia, um contrapeso de colar menat representa o rei Taharka com o amuleto cordiforme, enquanto é amamentado por Sekhmet. No registo inferior o deus Hórus está pousado, sob a forma de falcão, sobre um serekh real, rodeado pelas Duas Senhoras, Nekhbet e Uadjit ${ }^{(14)}$. Este tipo de representação enquadra-se na temática da coroação real e é normalmente representada neste contexto ritual para assinalar o nascimento da natureza divina do faraó. A celebração do nascimento divino do faraó parece ter sido, de facto, valorizada pelos reis cuchitas pois, desse modo, desvalorizavam a sua origem estrangeira. Outra representação real com o amuleto cordiforme é proveniente de Musaurat es-Sufra, no Sudão, e consiste num relevo do século III a. C, representando o rei núbio Arnekhamani(15). Apresentando uma indumentária muito elaborada, bem como o toucado hemhem usado pelos herdeiros divinos, o rei possui, entre as pesadas jóias, um amuleto cordiforme. A combinação do toucado e do amuleto faz supor uma identificação do rei com Horpakhered (Hórus Criança), a qual, como no relevo de Tutmés III, serve o propósito de reforçar a eficácia da acção real. 
Outras representações mostram o rei não a usar o amuleto mas sim a doá-lo como oferenda a uma divindade. Em Filae, na colunata de acesso ao templo de ísis, o faraó Alexandre é representado a oferecer dois vasos de unguentos a uma divindade. Na retaguarda é representado um amuleto do coração num suporte de vaso, o que indica que se trata de um amuleto de tipo vaso. Os amuletos cordiformes de tipo vaso podem, deste modo, ter sido usados no culto divino certamente com o intuito de conter substâncias rituais. Em Karnak, um outro faraó oferece a Montu dois amuletos cordiformes ${ }^{(16)}$. Neste caso, a dádiva é acompanhada pela seguinte inscrição:

Toma o teu coração ib para ti. O teu coração hati repousará no seu lugar.

Os dois corações constituem uma oferenda real, conotada com o coração ib, que tem como intuito fazer "repousar" ou "contentar" o coração hati do deus.

O uso do amuleto cordiforme nestes exemplos, embora semanticamente próximo (em todos os casos se pretende sublinhar a legitimidade e a pureza do herdeiro do trono) difere ao nível do significado específico que este símbolo desempenha em cada um destes momentos. Nas primeiras representações é a pureza do sangue que está em causa, ao passo que nas cenas do templo cenotáfio de Seti I detecta-se um sentido mais espiritual relacionado com a pureza do comportamento avaliada no tribunal de Osíris. As representações cuchitas procuravam, através do amuleto, assinalar o nascimento divino do rei e a sua identificação com um deus juvenil.

O peitoral de Tutmés III vem por fim alertar para a possibilidade do amuleto estar relacionado com determinadas cerimónias reais que conferiam ao rei o seu estatuto divino e asseguravam a sua função como intermediário divino. Outras representações asseguram que os amuletos cordiformes podiam ser usados no culto divino, quer sob a forma de vasos de unguentos, quer sob a forma convencional de amuletos, os quais eram oferecidos às deidades no âmbito do culto, o que concorre para estabelecer um forte elo entre estes objectos e o rei. Sucedem-se assim sentidos diferentes no uso do amuleto cordiforme ao longo do tempo, os quais tentaremos explicitar nas secções seguintes do nosso trabalho. 


\section{A representação do amuleto do coração nos súbditos reais}

\subsection{O amuleto cordiforme em estátuas, sarcófagos e outros objectos funerários}

\section{A XVIII dinastia}

Um amuleto cordiforme duplo é representado num famoso grupo escultórico, proveniente do esconderijo de Karnak, que representa Sennefer, o governador de Tebas que viveu sob o reinado de Amenhotep II (17). Para além do duplo amuleto cordiforme, este alto dignitário ostenta, em volta do pescoço, os chebiu, os pesados colares compostos por discos de ouro que eram atribuídos pelo rei como recompensa aos seus funcionários mais destacados. Esta associação entre o "ouro de honra" e o duplo amuleto cordiforme tem vindo a alicerçar a ideia segundo a qual o duplo amuleto "cardíaco" teria sido um privilégio raro concedido pelo rei a alguns dos seus funcionários. O facto é que Sennefer também se fez representar com este duplo amuleto no seu túmulo da necrópole de Cheikh Abd el-Gurna (TT 96). Nas representações mais detalhadas do seu túmulo observa-se uma coloração diferente nos dois corações que compõem o amuleto, sugerindo a evocação de materiais diferentes como o ouro e a prata. Além disso, no referido túmulo, os dois corações estão normalmente decorados com as cartelas reais de Amen-hotep II(18). Todos estes indícios apontam efectivamente para a possibilidade do duplo amuleto cardíaco ser uma condecoração real.

Apesar de raramente representado, este objecto surge pelo menos num outro túmulo da XVIII dinastia, desta vez na esplêndida sepultura de Khaemhat (TT 57), escriba real e inspector dos celeiros do Alto e do Baixo Egipto sob o reinado de Amen-hotep III. Neste túmulo, Khaemhat faz-se representar com uma ampla variedade de amuletos cordiformes $^{(19)}$ entre os quais se destaca um amuleto duplo gravado sobre o seu peito ${ }^{(20)}$. Para além de ser, com toda a probabilidade, uma condecoração real, o significado deste objecto não é fácil de apurar. Georges Legrain num artigo publicado há já cem anos, mas muitas vezes esquecido, chamou a atenção para o facto deste amuleto constituir uma transposição iconográfica do termo ibui (ibwi ). A tradução desta palavra não é consensual. Pode ser traduzida como um superlativo ("coração dos corações") ou "ícone" ou «imagem", no sentido 
de uma imagem divina. Com efeito, na terminologia religiosa, o termo pode ser usado da seguinte maneira: "Sokar é a imagem (ibwi) de Amon»(21). Um dado interessante é que em Karnak os faraós possuíam uma «imagem», ibui, que recebia um culto particular ${ }^{(22)}$. É possivel que os funcionários que apresentem esta condecoração estivessem envolvidos na manutenção de um tal culto ao rei. Nesse caso seriam, eles próprios, uma «imagem» do rei para os súbditos que não tinham a possibilidade de ver directamente o faraó. É claro que essa distinção os dotava de uma grande veneração e respeitabilidade.

Em ataúdes e sarcófagos também é possivel detectar representações do amuleto cordiforme, sempre localizadas no peito do defunto. Os três exemplares datados deste período evidenciam características muito semelhantes. $O$ amuleto é representado suspenso sobre um fio de contas grosso disposto, em geral, sobre um largo colar usekh. As mãos do defunto ladeiam o amuleto e, em alguns casos, ostentam os signos djed e "nó de Ísis", tjit. O mais antigo exemplar remonta ao reinado de Tutmés III e foi construído para Amen-hotep, o "superior dos construtores de Amon»(23). Maherpa, amigo íntimo do rei Tutmés IV, foi outra grande personalidade a ser recompensada com uma destas representações ${ }^{(24)}$. O sarcófago de Khai, um alto funcionário do rei sepultado na Núbia, actualmente conservado no Museu de Elefantina, apresenta também um grande amuleto cordiforme ${ }^{(25)}$.

Também na XVIII dinastia se começou a gravar o amuleto cordiforme sobre as estatuetas funerárias. A razão para esta incidência deve estar relacionada com uma das funções destas estatuetas, que era a de constituir uma réplica da múmia ou do sarcófago antropomorfo(26). A presença dos amuletos cordiformes nos ataúdes foi, com toda a probabilidade, o factor que espoletou a sua representação nas estatuetas funerárias. As estatuetas adornadas com o amuleto cordiforme são, em geral, belos e imponentes exemplares, acusando o elevado estatuto social dos seus proprietários. Tal é o caso de uma estatueta de luia, uma das mais eminentes individualidades do reinado de Amen-hotep

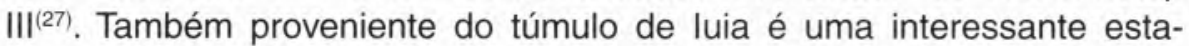
tueta funerária do defunto sob a forma de uma ave $b a^{(28)}$. Também aqui o amuleto foi pintado em redor do pescoço da ave. Neste caso, a representação do amuleto relacionava-se, deste modo, com um dos principais atributos do ba: manifestar-se como um poder luminoso capaz de empreender a saída para o $\mathrm{dia}^{(29)}$. 


\section{O período ramséssida}

Um outro grupo escultórico funerário, da XIX dinastia, apresenta dois irmãos com os nomes de Siset e de Meriptah (este último era escriba real), ambos adornados com o amuleto cordiforme ${ }^{(30)}$. Embora em número muito reduzido, o mesmo amuleto também é detectado na decoração de sarcófagos deste período ${ }^{(31)}$.

Representações do amuleto foram igualmente encontradas em estatuetas funerárias feitas em pedra ${ }^{(32)}$ e em faiança ${ }^{(33)}$. Se, nos objectos de faiança, o trabalho se afigura sumário, nos de pedra a qualidade de execução mantém-se de nível muito elevado (algumas destas figurinhas representavam um capataz $^{(34)}$, o que poderá explicar a sua qualidade). Outros motivos, como a ave ba ou os elaborados colares usekh, complementam a decoração destes delicados objectos.

\section{O Terceiro Período Intermediário}

Do Terceiro Período Intermediário a representação do amuleto nas estatuetas funerárias entrou em desuso ${ }^{(35)}$. A raridade do amuleto neste tipo de estatuária contrasta com a sua pródiga representação sobre os ataúdes da época. Embora a representação de amuletos cordiformes no peito dos sarcófagos do período ramséssida pareça ter caído em desuso, os ataúdes da XXI dinastia recuperaram largamente esta prática. Deste modo, sobretudo nos ataúdes mais elaborados, é possível encontrar com frequência o amuleto do coração representado no peito do defunto. Em, torno do amuleto cordiforme aglutina-se, de um modo geral, um sem número de representações com um grau de complexidade variável seguindo uma tendência, comum neste período, de preencher profusamente todo o espaço disponível, fenómeno habitualmente designado por horror vacui ${ }^{(36)}$. As representações mais simples apresentam o amuleto, suspenso por uma corrente, rodeado pela ave benu e pela barca solar. No entanto, as representações dos ataúdes também incluem símbolos osiríacos de grande significado como o tauer, o signo udjat, tecendo, deste modo, uma ligação muito estreita entre os símbolos solares-osiríacos e o amuleto do coração, o qual se afigura como um veículo aglutinador destes elementos simbólicos ${ }^{(37)}$.

Noutros casos, o amuleto é disposto no seio de um elaborado peitoral com um elevado valor simbólico. Em certos ataúdes voltamos a encontrar um peitoral muito elaborado composto por um amuleto cordiforme encimado por um disco solar ladeado por duas serpentes 
sagradas $^{(38)}$. Trata-se do mesmo peitoral representado em Deir el-Bahari sobre o peito de Tutmés III-Hatchepsut. Verifica-se, deste modo, a apropriação de um objecto que, na XVIII dinastia, possuía fortes conotações com a realeza, e que, na XXI dinastia, é frequentemente representado entre os sacerdotes de Amon. O simbolismo deste objecto, vincadamente solar, remete para a associação entre o coração e sol. Do ponto de vista simbólico, o peitoral faz alusão ao despertar de uma consciência iluminada. É, no entanto, interessante constatar que em Tutmés III este acontecimento justificava o estatuto divino do faraó e tinha lugar em vida, ao passo que, entre os sacerdotes de Amon, era um atributo funerário e estava conotado com a ressurreição.

O ataúde de Direpu, uma cantora de Amon, apresenta um outro peitoral com a representação de uma ave ba ladeada por amuletos do coração de cor negra ${ }^{(39)}$. Os amuletos do coração estão encimados por discos solares vermelhos, ao passo que a ave ba possui um disco negro sobre a cabeça. Também aqui a representação do coração se fez rodear de símbolos solares conotados com o poder divino da luz.

O peitoral representado sobre a cobertura de múmia de Padiamon, um sacerdote de Amon que viveu sob o pontificado de Pinedjem II, apresenta uma imagem muito sugestiva, de outro peitoral alusivo ao coração ${ }^{(40)}$. Neste caso, um escaravelho criocéfalo alado, simbolizando o sol nocturno, segura entre as patas traseiras um amuleto do coração encimado por um disco solar ladeado por duas serpentes. Trata-se novamente de um desenvolvimento da ideia já presente numa representação anterior: o despertar de uma consciência iluminada como símbolo da ressurreição(41). Nos ataúdes soberbos de Pinedjem II e de Nesikhonsu, encontramos, na região do peito, elaboradas composições com um programa simbólico semelhante ${ }^{(42)}$. No epicentro destas composições está o escaravelho Khepri(43), empunhando nas patas dianteiras o disco solar e, nas patas traseiras, o coração. Todas estas composições ilustram a regeneração do disco solar ocorrida no mundo inferior. A associação entre o amuleto do coração e o escaravelho alado não pressupõe, no entanto, uma identificação entre estes dois importantes símbolos. Pelo contrário, a dualidade entre o amuleto cordiforme e o escaravelho serve de pretexto para ilustrar uma outra relação dinâmica que marca a teologia egípcia pós-amarniana: a síntese solar-ctónica que se manifesta na união entre Ré e Osíris(44). Os dois símbolos da consciência tornavam-se assim na base para a identificação do defunto com as duas facetas do grande deus. $\mathrm{O}$ amuleto cordiforme materializava a faceta osiríaca e ctónica do defunto, ao passo que o 
escaravelho alado fazia alusão à sua manifestação solar(45). Os elaborados peitorais representados nos ataúdes deste período exprimem, deste modo, a associação do defunto aos aspectos solares e ctónicos do grande deus. Com estas representações o defunto associava-se ao eterno curso do sol, ao seu perpetuum mobile, mas também se identificava com o triunfo de Osíris sobre a morte ${ }^{(46)}$.

\section{A Época Baixa}

A Época Baixa oferece-nos os últimos exemplares de amuletos do coração representados sobre sarcófagos ${ }^{(47)}$. Nestas antiguidades, o programa iconográfico é simplificado e o espaço assim libertado foi utilizado para a redacção de textos funerários ${ }^{(48)}$. É por essa razão que, pela primeira vez neste contexto arqueológico, se começou a representar o amuleto do coração em conjunto com o capítulo 26 do "Livro dos Mortos". Apesar da inflexão resultante da mudança do programa decorativo destes sarcófagos, alguns símbolos como o escaravelho alado e a ave ba continuaram a ser associados à representação do amuleto do coração, ainda que sem a densidade iconográfica da XXI dinastia. A associação entre o escaravelho sagrado e o amuleto do coração permite constatar que o simbolismo dualista estabelecido no Terceiro Período Intermediário continuou a vigorar na Época Baixa.

Alguns exemplares tardios apresentam aos pés dos ataúdes antropomórficos a representação de sandálias decoradas com a silhueta tradicional dos inimigos do Egipto. Em alguns casos, as representações dos inimigos, que se destinavam a ser pisadas pela múmia como demonstração da sua justificação, apresentam estranhamente um amuleto que parece identificar-se com o amuleto cordiforme. Neste caso, o amuleto cordiforme parece ter sido utilizado para evocar o sacrifício dos inimigos e a exteriorização do coração, o sede do seu poder de vida, para demonstrar o poder do defunto para triunfar da morte e dos adversários da ordem cósmica.

\section{A Época Greco-Romana}

Na Época Greco-Romana o amuleto do coração desapareceu da decoração do peito dos sarcófagos para passar a ser representado unicamente nas máscaras funerárias ${ }^{(49)}$. A transferência da representação do coração para a região do pescoço foi gradual e detecta-se já 
em alguns ataúdes da Época Baixa ${ }^{(50)}$. Pintado esquematicamente em cor vermelha e suspenso numa gargantilha de contas da mesma cor, o amuleto tornou-se um adereço comummente representado no pescoço da máscara. Nenhum outro elemento simbólico nos esclarece sobre o significado particular deste amuleto nestes objectos. A mudança da localização desta representação poderá reflectir uma mudança do significado do amuleto? As razões mais óbvias parecem simplesmente relacionar-se com uma mudança na valorização das coberturas de cartonagem que cobrem as múmias deste período, as quais se tornaram um alvo preferencial da decoração, em detrimento do ataúde ${ }^{(51)}$. No entanto, considerando os elementos que já temos reunido até ao momento a partir de outras fontes, a possibilidade de uma mudança de sentido do amuleto também é plausível. A viragem interpretativa deste amuleto repercutiu-se, por exemplo, no facto do amuleto perder a ligação privilegiada à região do peito. A representação do amuleto nas máscaras é, deste modo, mais um indicador que reforça a ideia que, a partir da Época Greco-Romana, o amuleto é usado com um valor apotropaico íntrinseco susceptível de ser canalizado para proteger qualquer parte do corpo.

\subsection{O amuleto cordiforme na decoração tumular}

Uma das fontes privilegiadas para compreender o significado do amuleto cordiforme é a decoração tumular onde efectivamente surge em variados contextos simbólicos e rituais constituindo, a par com o escaravelho do coração, o amuleto mais representado no contexto tumular. Apresentamos em seguida alguns dos contextos de representação em que o amuleto é mais frequentemente representado.

\section{O uso do amuleto cordiforme nas representações do culto funerário}

No que diz respeito ao uso do amuleto do coração no culto funerário, o "Livro dos Mortos» de Nebseni constitui um testemunho único, não só por consistir num dos primeiros exemplares do "Livro dos Mortos" conhecidos, como por apresentar um uso deste amuleto radicalmente distinto daquele que observamos na maior parte das representações funerárias datadas sobretudo de períodos posteriores. $\mathrm{Na}$ vinheta que representa o culto funerário garantido pelo seu filho 
primogénito, Ptahmés, o amuleto foi colocado ao peito do herdeiro e não do defunto, como será a regra em períodos posteriores ${ }^{(52)}$.

Com efeito, em todas as restantes cenas similares inventariadas, é o defunto (na esmagadora maioria o chefe de família) que ostenta 0 amuleto( ${ }^{(53)}$. Tomando como exemplo deste tipo de utilização do amuleto, a representação do túmulo de Nebenmaet (TT 219) ${ }^{(54)}$, da XIX dinastia, que também apresenta o casal diante do primogénito, Uepmés, vemos facilmente a grande diferença de horizonte que separa as duas representações. No caso do papiro de Nebnesi, o amuleto foi usado de modo a sublinhar o papel de Ptahmés como primogénito, enquanto que, na representação de Nebenmaet, o amuleto tem um valor exclusivamente funerário. Curiosamente o uso do amuleto por Ptahmés aproxima-se do significado que este amuleto possuía numa das suas primeiras ocorrências, ou seja, na representação do príncipe herdeiro de Ahmés. Estas representações sugerem, deste modo, que o primeiro significado do amuleto se reportava ao estatuto de herdeiro (primeiramente aplicado à família real e posteriormente alargado para um uso "doméstico" e privado).

Já na XVIII dinastia, mas sobretudo a partir do período ramséssida, este significado foi claramente secundado em benefício de uma interpretação religiosa relacionada com as expectativas da vida no Além, sendo então mais associado ao morto do que ao garante do culto funerário. Nesta linha, o amuleto contribuía para assinalar a condição social do defunto. Note-se que, nas representações de casais, a mulher nunca apresenta o amuleto. $\mathrm{Na}$ verdade, as representações do amuleto em mulheres são muito raras e, quando ocorrem, assinalam um estatuto social bastante elevado, como é o caso da dama Nesitanebetacheru, filha do sumo sacerdote de Amon, Pinedjem II, e de Nesikhonsu(55).

Não obstante, o amuleto é ocasionalmente representado, no contexto funerário, como um adereço usado pelos vivos. Tal é o caso de um ataúde da XXII dinastia, que representa um cortejo funerário onde os puxadores do carro mortuário, vestidos com luxuosos trajes cerimoniais, todos apresentam o amuleto cordiforme ${ }^{(56)}$. Longe de serem meros servidores, a sua indumentária mostra bem a dignidade da sua posição. $\mathrm{O}$ uso do amuleto cordiforme por estas seis personalidades faz pensar num uso deste objecto como privilégio de um círculo restrito de indivíduos que presta homenagem ao defunto.

Pela análise destes dados afiguram-se assim três tipos de usos. No início da XVIII dinastia, o amuleto era usado pelos vivos, como 
reflexo da sua legitimidade para garantir o culto funerário. Sobretudo a partir do período ramséssida, o amuleto era usado preferencialmente pelo defunto como sinal da sua condição social e estatuto. Finalmente, no Terceiro Período Intermediário, para além de se manter o uso do amuleto pelos defuntos justificados, o amuleto parece continuar a ser ocasionalmente usado pelos vivos como sinal distintivo. Estes dados permitem pensar que os dois tipos de usos talvez nunca tivessem deixado de coexistir, muito embora o seu peso e importância flutuasse ao longo do tempo.

\section{O amuleto cordiforme nas representações da psicostasia}

O amuleto cordiforme assinala, em primeiro lugar, a justificação do defunto. Por essa razão, as representações do amuleto são alusivas quer à psicostasia, quer à adoração de Osíris, a qual comentaremos na rubrica seguinte. As representações da psicostasia na XXI dinastia tornam explícito um dado que já em representações anteriores se adivinhava. No Além, o defunto recebia o amuleto cordiforme na própria pesagem do coração(57). Normalmente, o homem recebe 0 amuleto e adopta uma atitude de júbilo muito característica elevando os braços de forma exuberante e agitando penas maéticas que simbolizam a justificação( ${ }^{(58)}$. É bastante claro que, nestes casos, o amuleto cordiforme constitui uma recompensa pelo resultado obtido na psicostasia. Este uso do amuleto cordiforme evoca o seu antigo uso como condecoração real. O significado político parece assim ter sido secundado em função do significado religioso: a condecoração real transforma-se em condecoração osiríaca.

\section{0 amuleto cordiforme nas representações da adoração de Osíris}

Uma das vinhetas mais importantes do "Livro dos Mortos" apresenta o defunto a adorar Osíris, como resultado da sua justificação. Nestas circunstâncias, o defunto apresenta um amuleto cordiforme ${ }^{(59)}$. No exemplar do "Livro dos Mortos" do arquitecto Kha e da sua muIher Merit, descoberto em Deir el-Medina (TT 8), o casal apresenta-se diante de Osíris numa grande e bela vinheta, em que Kha usa um amuleto cordiforme em ouro. O papiro funerário de luia (descoberto no túmulo KV 46) também apresenta uma vinheta que, embora em 
mau estado de conservação, permite constatar que esta grande personalidade do reinado de Amen-hotep III também usava um tal amuleto. luia apresenta-se diante de Osíris com a esposa, Tuia, elevando os braços num gesto de adoração( ${ }^{(60)}$.

Mas o testemunho mais importante deste conjunto de representações é a apresentação de Merenptah diante de Osíris, gravada nas paredes da "Câmara funerária" do Osireion de Abido(61). Levando a mão ao amuleto, o faraó é conduzido por Anúbis diante de Osíris. O significado do amuleto neste tipo de cenas é explicitado pela própria inscrição que acompanha estas imagens:
A perfeição dele é grande (...) na balança
(Ele) está isento de culpas abomináveis, nada foi encontrado, não existe nele (qualquer) mal (...),
o seu coração ib está no corpo,
○ (seu) coração hati é firme (men).

O amuleto cordiforme está inequivocamente em relação directa com o resultado obtido na psicostasia. Nas próprias vinhetas da psicostasia, com efeito, a apresentação do defunto diante de Osíris constitui, em geral, a consequência natural de um resultado favorável. Uma representação tumular da necrópole tebana (TT 255) apresenta o escriba real Rai e a sua mulher, Nebet-taui, conduzidos por Horsaiset à presença de Osíris ${ }^{(62)}$. Ambos apresentam o braço cruzado diante do peito, um gesto codificado que traduz habitualmente a posição adoptada diante de um tribunal. No entanto, é apenas o homem, Rai, quem ostenta o amuleto. Como no relevo de Merenptah, o amuleto está conotado com o resultado positivo na psicostasia.

\section{O amuleto cordiforme nas representações da vida do Além}

Outro tipo de representações coloca o portador do amuleto cordiforme diante de situações características do mundo dos mortos. No túmulo de Nebenmaet (TT 219), da XIX dinastia, este zeloso "servidor do Lugar de Verdade" (sedjem-ach em Set-Maet) foi representado a jogar o jogo do senet com a sua esposa, Meretseguer. O jogo do senet, de grande valor simbólico na vida no Além, constituía uma imagem evocativa do jogo do destino ${ }^{(63)}$.

É frequente a decoração dos ataúdes antropomórficos da XXI dinastia incluir a representação do defunto dotado com o amuleto cordi- 
forme. Tal é o caso da figuração do defunto diante da deusa árvore, um aspecto funerário da deusa Hathor, a receber alimentos e bebidas revitalizadoras do dom da vida ${ }^{(64)}$. Nestes contextos de representação, as dádivas oferecidas ao defunto parecem constituir, em última análise, os benefícios atribuídos aos justificados, ou seja, aos que, em resultado da sua virtude, receberam o amuleto cordiforme.

Outros benefícios menos tangíveis também podiam ser atribuídos na sequência da justificação. Nestes casos, o amuleto cordiforme abria as portas para o contacto com as divindades do Além. No túmulo de Irinefer (TT 290), por exemplo, o defunto apresenta o amuleto numa atitude respeitosa perante a ave benu enquanto navega na barca solar diurna. No túmulo de Khakhebenet (TT 2), o defunto presta louvor a Tot, que adopta a configuração de babuíno.

Noutro tipo de representações mais complexas, o defunto apresenta o amuleto cordiforme enquanto participa nos grandes acontecimentos cósmicos que marcam a viagem no mundo inferior. No túmulo de Amenemopet (TT 41) podemos identificar três representações relacionadas com o amuleto cordiforme. Em duas delas o defunto segura numa das mãos o símbolo do vento, aludindo ao sopro da vida e leva a outra mão ao peito para segurar o amuleto cordiforme. Nesta posição, o defunto assiste ao seu próprio encontro com Anúbis, ao passo que, num outro registo, assiste à sua faina nos Campos de laru. $\mathrm{Na}$ mesma parede, outra representação de Amenemopet mostra a estátua do ka munida com o amuleto do coração diante de representações do Além que mostram o lago de fogo e o combate de Apopis.

Nas representações da vida do Além datadas da XXI dinastia, o defunto munido com $\mathrm{o}$ amuleto cordiforme podia assistir às grandes encenações divinas que garantiam o equilíbrio cósmico. A misteriosa regeneração do disco solar ${ }^{(65)}$, o triunfo da barca solar sobre a serpente Apopis ${ }^{(66)}$ ou as manobras de Tot para fazer "uma abertura no céu»(67) (correspondente ao capítulo 161 do "Livro dos Mortos»(68) são exemplos de ocorrências que fazem relacionar o amuleto cordiforme com a vitória do sol sobre as trevas, da qual depende a regeneração do $\operatorname{cosmos}^{(69)}$.

Analisando estas representações, constatamos, em primeiro lugar, que as experiências às quais o defunto justificado podia aceder no Além possuíam, na $\mathrm{XXI}$ dinastia, um carácter bastante mais abrangente do que as que estavam previstas no período ramséssida. De um modo geral, o amuleto do coração assinala as recompensas dadas ao defunto na qualidade de um justificado, um aliado da luz e da 
ordem cósmica. É nessa qualidade que o amuleto abria ao defunto as portas para a sobrevivência no Além e Ihe concedia a possibilidade de se alimentar, de "ver" os deuses e, sobretudo, de sair para o dia e encaminhar-se para os Campos de laru, integrando a tripulação de Ré e participando no combate contra as forças do caos. Por fim, um peitoral pertencente a uma dama com o nome de Mehitkhati apresenta uma representação bastante ilustrativa sobre o significado funerário do amuleto cordiforme ${ }^{(70)}$. A dama ergue as duas mãos em direcção ao amuleto situado no peito, num gesto que imita o da deusa Nut por ocasião do nascer do sol. A representação faz, deste modo, alusão ao despertar da consciência e da vida no Além, como consequência da justificação.

\section{0 amuleto cordiforme nas representações dos rituais de purificação}

$\mathrm{Na}$ decoração tumular da necrópole tebana o amuleto cordiforme foi muito frequentemente reproduzido em cenas relacionadas com a purificação(71). Convém, antes de mais nada distinguir dois tipos de representações que envolvem a purificação. Em certos casos, a purificação destina-se a ser empreendida sobre a estátua do ka. Nestas circunstâncias a purificação é desempenhada simplesmente pelo sacerdote do culto funerário, o sacerdote sem. Purificações deste tipo foram representadas, por exemplo, no túmulo de Sennefer (TT 96) e no túmulo de Siesi ${ }^{(72)}$, em Abido, onde parecem estar relacionadas com o ritual da abertura da boca. Nestas representações o amuleto do coração foi colocado sobre a estátua do ka e não sobre o defunto.

Outro tipo de purificação mais complexa envolve habitualmente um conjunto variável de sacerdotes distribuídos na composição em quatro grupos, podendo ainda contar com um número alargado de sacerdotes que assiste à cerimónia. Representações deste tipo podem ser encontradas também no túmulo de Sennefer (TT 96) ${ }^{(73)}$, Ramés (TT 55), ambos detentores do cargo de governador de Tebas, nos reinados de Amen-hotep II e Amen-hotep III, respectivamente. Ainda da XVIII dinastia figura a cerimónia de purificação do túmulo de Duauneheh (TT 125). Do período ramséssida, perfila-se ainda a cena de purificação representada no túmulo de Userhat (TT 51) ${ }^{(74)}$. Uma derivação deste tipo de purificação consiste na substituição dos sacerdotes pelos próprios deuses. É o que sucede, no período ramséssida, no túmulo de Neferabu (TT 5) ${ }^{(75)}$ e no relevo de Merenptah, 
talhado no Osireion de Abido, onde os sacerdotes foram substituídos por Hórus e Tot e por Tot, respectivamente ${ }^{(76)}$. Na XXI dinastia, no ataúde de Amenemopet, o ritual é celebrado por Anúbis e uma divindade indeterminada ${ }^{(77)}$.

Como se detecta pela própria evolução do tema, este segundo grupo de representações relacionado com a purificação apresenta afinidades simbólicas com a purificação real celebrada nos templos divinos, destinada a garantir a pureza necessária para o culto ou assinalando o nascimento divino do faraó, no ritual da coroação. Nestas representações, o defunto está posicionado, em pé ou acocorado, sobre uma taça ou um pedestal de pedra (algumas destas taças assumem a configuração do signo hieroglífico heb, que significa "festa", e que consiste precisamente numa taça de calcite). O defunto tem, em geral, uma veste cerimonial e, pelo menos, no caso de Ramés, apresenta uma aparatosa veste usada pelos vizires.

Em certos túmulos, como no caso de Sennefer e de Ramés, estas representações estão intimamente ligadas à saída para o dia. No caso do relevo de Merenptah no cenotáfio de Abido, a lustração tinha o intuito de conduzir o faraó à cripta onde este era regenerado no seio de Nut(78). Num caso como no outro a purificação apresenta fortes conotações solares. O número de quatro (grupos de) sacerdotes envolvidos nesta cerimónia é certamente inspirada na purificação real cujo objectivo, segundo Gardiner, era o de conceder ao rei o poder sobre os quatro pontos cardeais (afinal sobre o mundo), restaurando a unicidade do seu poder e assegurando o seu estatuto divino e o seu nascimento como netjer nefer ${ }^{(79)}$.

A iconografia envolvida em certas representações reforça, com efeito, a ideia de universalidade inspirada no nascer do sol. Na purificação de Sennefer, o defunto emerge da colina montanhosa como o sol renascido. Trata-se, com efeito, da representação de uma lustração solar que, a partir do período ramséssida, dará origem ao ritual de elevação da múmia no monte de areia, o qual apresenta uma forte conotação associada à saída para o dia.

Nas representações mais recentes, esta lustração é assegurada por duas divindades, parecendo decalcar, mais do que nas representações anteriores, o modelo de purificação real e assim reforçar as conotações solares envolvidas nesta lustração. A cerimónia decalcava, deste modo, o ritual que assegurava o despertar da centelha divina do faraó.

Qual seria então o papel do amuleto do coração neste tipo de representações? Como vimos, o amuleto cordiforme parece estar, no 
contexto funerário, estreitamente associado à justificação, ao ponto de poder ser perspectivado como uma recompensa que sinalizava virtude e rectidão. $O$ resultado favorável na psicostasia garantia que o defunto pudesse assimilar-se ao ciclo de renovação perpétua do sol. O papel do amuleto cordiforme no ritual da purificação parece, deste modo, reportar-se à pureza requerida para a integração do defunto no circuito solar. O amuleto assinalava, como já foi referido anteriormente, a justificação do defunto, ou seja, a sua proclamação como um aliado no combate contra os inimigos da luz e representava o potencial de virtude acumulado durante a vida terrena graças à sabedoria e à prática da maet. Em suma, o amuleto cordiforme assinalava que o novo nascimento do defunto se verificava graças à sua pureza e à sua sabedoria, ou seja, à sua capacidade para realizar a maet.

\section{Considerações finais}

Em conclusão, em quase todos os contextos de representação observados, o amuleto cordiforme parece dever a sua "popularidade" ao facto de simbolizar o coração puro graças à prática da maet. As representações estudadas sugerem que este objecto começou por estar associado à realeza, estando conotado com a legitimidade real para exercer o poder e assegurar a manutenção da ordem cósmica. A partir do reinado de Tutmés III o amuleto começou a ser representado como um objecto que era atribuído pelo rei ao funcionário, ainda em vida, como um sinal distintivo de pureza e de sabedoria, simbolizando a consciência maética do funcionário. A raridade dos testemunhos e o elevado nível social dos detentores de um tal objecto apontam para que, sobretudo na necrópole tebana, o amuleto cordiforme tivesse sido concedido pelo rei como um privilégio atribuído a um círculo muito restrito de individualidades que tinham o privilégio de rodear o rei. Esta recompensa real, que assinalava um estatuto especial durante a vida terrena, prolongava-se no Além, uma vez que garantia a justificação destes eleitos no tribunal de Osíris. Talvez seja essa a razão que explique a representação destes objectos no peito dos sarcófagos da XVIII dinastia, bem como o seu quase desaparecimento durante o período amarniano, uma vez que o objecto simbolizava um privilégio real concedido aos súbditos. Como é sabido, na reforma de Amarna verificou-se um retrocesso drástico no que toca à "democratização" do contacto como sagrado. Ao representar a consciência maética, o amuleto 
cordiforme simbolizava a faculdade faraónica de se alinhar com a ordem cósmica. É sintomático que após a reforma de Amarna, o amuleto tenha recuperado todo o seu prestígio, muito embora pareça ter-se desprovido do seu valor político para se afirmar como um símbolo da justificação de Osíris.

É a inclusão do amuleto no seio do imaginário da justificação que poderá explicar a representação do amuleto cordiforme nos inimigos do Egipto. Neste âmbito o amuleto representa o poder de vida que é arrancado às criaturas setianas para beneficiar o defunto. Trata-se de um desenvolvimento do significado que esteve sempre subjacente ao amuleto e que consiste em afirmar o poder da luz para repelir o caos e instaurar a ordem cósmica. O amuleto cordiforme adquiria assim o estatuto de um objecto que assinalava a reposição da justiça através do poder para repelir e vencer as forças maléficas conotadas com Set.

Um conjunto enigmático de esboços desenhados e pintados sobre óstracos, datados provavelmente do período ramséssida, afiguram-se de difícil interpretação. Contrastando fortemente com o carácter diferenciado que está associado à maior parte das representações do amuleto cordiforme, aqui são indivíduos desgrenhados, a acompanhar touros $^{(80)}$, ou uma insólita amazona de cabelos igualmente agitados, que fazem gala em mostrar o prezado amuleto ${ }^{(81)}$. $\mathrm{Na}$ ausência de elementos escritos que esclareçam a natureza e o significado destas representações, parece-nos provável que se tratem de representações de carácter satírico ou anedótico, muito frequentes sobre este tipo de suporte. Num destes óstracos figura, com efeito, uma imagem típica das representações satíricas, misturando figuras humanas e animais. Trata-se de um macaco, representado a tocar uma flauta dupla, acompanhado por uma jovem nua, adornada por colares, idênticos aos que são representados sobre as estatuetas de concubinas, e um amuleto do coração ${ }^{(82)}$. Sublinhe-se ainda que, no contexto do Império Novo, as representações de mulheres com este amuleto são quase inexistentes. Na maior parte dos casos são homens de elevado estatuto social que usam o objecto. Nestes óstracos, pelo contrário, são as mulheres, meras bailarinas ou inverosímeis amazonas, bem como humildes pastores que usam o amuleto. Se estas representações datassem da Época Baixa ou períodos posteriores bem poderíamos aceitar o valor documental destes objectos, pois sabemos que nesta época o amuleto se vulgarizou. No entanto, mediante os dados que possuímos para o Império Novo, uma tal hipótese parece-nos pouco provável 
pois é notório, em todas as fontes, o inegável valor simbólico que o objecto possuía. Mais provável é que estas representações tivessem um valor satírico e constituíssem uma forma velada de ridicularizar os grandes, recorrendo a um símbolo, o amuleto cordiforme, ainda associado, nesse período, à classe dominante.

\section{Notas}

(1) SOUSA, "Os amuletos do coração no antigo Egipto: Tipologia e caracterização", Cadmo 15 (2005), pp. 105-130.

(2) MALAISE, "La signification des pendentifs cordiformes dans l'art égyptien", CdÉ 50 (1975), pp. 105-135.

(3) MALAISE, Les Scarabées de coeur dans l'Égypte Ancienne, Monographies Reine Élizabeth, Bruxelas, 1978.

(4) Ver SOUSA, A simbólica do coração no Antigo Egipto: estudo de antropologia religiosa sobre a representação da consciência, dissertação de doutoramento em História, Faculdade de Letras da Universidade do Porto, Porto, 2006.

(5) Ver Museu Egípcio do Cairo, CG 3.

(6) Devido às conotações aquáticas, a tartaruga estava associada ao Nun e, por isso, associada às forças hostis à luz. Paradoxalmente, o amuleto em forma de tartaruga era usado para afastar os poderes das trevas. Ver ANDREWS, Amulets of Ancient Egypt, University of Texas Press, 1998, p. 36.

(7) Ver Museu Egípcio do Cairo (RT 18.4.22.4).

(8) Ver SOUSA, "Os amuletos do coração no antigo Egipto: Tipologia e caracterização", Cadmo 15 (2005), p. 119-120.

(9) Ver Anexo IV da referida tese.

(10) Encontrada em fragmentos sucessivos entre os blocos que enchiam o terceiro pilone de Karnak, a estela tem vindo a ter uma leitura cada vez mais completa. Para conhecer o conteúdo deste documento ver HARARI, "Nature de la Stéle de Donation de Fonction du roi Ahmôsis a la reine Ahmès-Nefertari”, em ASAE 56 (1956), pp. 1-63.

(11) Museu Egípcio do Cairo, JE 98831.

(12) Segundo terraço de Deir el-Bahari, colunata meridional.

(13) Ver FRANKFORT, The Cenotaph of Seti I at Abydos, vol. II, Egypt Exploration Society, Londres, 1933, Plate LXXII.

(14) Ver Metropolitan Museum of Art, 41.160.104.

(15) A representação encontra-se no templo de Apedemak, em Musauarat es-Sufra. Ver WENIG, Africa in Antiquity: The Arts of Ancient Nubia and the Sudan, Vol. I, Brooklyn Museum, Brooklyn, 1978, p. 96.

(16) Trata-se do portal monumental de Evergeta, erguido diante do templo de Khonsu no período ptolemaico. A representação encontra-se na face meridional do portal.

(17) Museu Egípcio do Cairo, JE 36574 (CG 42126). 
(18) Apenas num caso apresenta um nome distinto: trata-se de Alexandre, uma "usurpação» tardia resultante certamente da visita de um viajante estrangeiro.

(19) Khaemhat apresenta o amuleto cordiforme simples, integrado num peitoral com os signos djed e "nó de Ísis" e ainda um duplo amuleto do coração.

(20) A representação faz parte de um grupo escultórico composto por si e por um outro "colega" de profissão. O critério para a constituição destes grupos escultóricos não é claro e provavelmente obedeceu apenas à vontade dos seus possuidores. $O$ grupo de Sennefer representa-o com uma mulher e a filha, ao passo que Khaemhat está acompanhado por um colega, Imhotep, também ele escriba real.

(21) Estátua 409 do esconderijo de Karnak, em LEGRAIN, "Le mot ibwy, image, icone», RT 11 (1905), p. 181.

(22) A estátua 122 do esconderijo de Karnak menciona um "sacerdote puro do ibwi do rei Osorkon": "Eu fiz o ibwi de Djeserkaré, o justificado, em ouro e todas as pedras preciosas (...)". Nesta passagem o ibwi era uma imagem divina, do deus ou de um rei divinizado.

(23) Eton College, ECM 1876.

(24) Museu Egípcio do Cairo, JE 31378 (CG 4219).

(25) Museu de Elefantina, N. ${ }^{\circ} 2686$.

(26) Efectivamente a estatueta funerária constituía um "duplo" da múmia e era a sua miniatura (ver Luís Manuel de ARAÚJO, Estatuetas Funerárias Egípcias da XXI dinastia, Textos Universitários de Ciências Sociais e Humanas, Fundação Calouste Gulbenkian-FCT, Lisboa, 2003, p. 108). Inicialmente, a função destas estatuetas deve-se ter limitado a esta função, só posteriormente vindo a adquirir a função de substituir o morto nos trabalho do Além o que levou a inscrever o capítulo 6 do "Livro dos Mortos". As primeiras destas miniaturas remontam à $\mathrm{XI}$ dinastia e a sua criação pode relacionar-se com a obrigatoriedade, introduzida no Império Médio, de prestar trabalho em obras públicas (ver SHAW, The Oxford History of Ancient Egypt, Oxford University Press, Oxford, 2002, p. 182).

(27) Museu Egípcio do Cairo, SR 95368 (CG 51033).

(28) Museu Egípcio do Cairo, JE 95312.

(29) Sobre a importância desta característica no Império Novo ver ZABKAR, "A study of the Ba concept in Egyptian texts", SAOC, 34, 1968, p. 141.

(30) Kunsthistorisches Museum, N. Inv. 48.

(31) Desta feita apenas registámos uma ocorrência: Museu Egípcio do Cairo (14/11/24/3.

(32) Por exemplo, Museu Egípcio do Cairo, JE 22170 (CG 47229).

(33) Cleveland Museum of Art, 1914.589.

(34) A figura do capataz surgiu neste período como uma nova modalidade destas estatuetas. É o caso de um exemplar conservado Museu Egípcio de Berlim (N. Inv. 4401).

(35) Um dos raros exemplos desta época conserva-se no Museu Egípcio do Cairo (CG 46829).

(36) Em NIWINSKI, XXI dynasty Coffins from Thebes: Chronological and Typological Studies, Verlag Philipp von Zabern, Mainz am Reihn, 1988, p. 78. Deste modo, a ladear o amuleto é muito provável encontrar a ave benu, o deus Khepri, deusas aladas (com forma humana ou com forma de serpente), o deus Anúbis, mas também objectos inanimados 
como o totem de Abido, tauer, e certos hieróglifos, como os signos udjat, nefer e neb. Debaixo do amuleto encontra-se frequentemente um peitoral alusivo a Khepri, ou a deusa Nut com as asas estendidas sobre o defunto, ao passo que, sobre o amuleto podem ser dispostas várias representações: o deus Khepri, o disco solar, o totem tauer ou dois vultos divinos sem uma identidade definida.

(37) De notar que, na tipologia apresentada por Andrzej Niwinski para classificar os ataúdes da XXI dinastia, são sobretudo os ataúdes de tipo III que mais frequentemente apresentam este tipo de representações. Estes ataúdes, datados do pontificado de Pinedjem II, caracterizam-se por possuírem um grande colar usekh que se sobrepõe totalmente aos braços, deixando apenas as mãos expostas. A tipologia é apresentada em NIWINSKY, op. cit, pp. 67-96.

(38) O peitoral representado na cobertura de múmia de Unet tem uma forma rectangular e apresenta, no centro, um coração negro, encimado por um disco solar vermelho, ladeado por duas serpentes, também elas encimadas por discos solares. Sobre a tampa do ataúde de Unet foi representada uma composição idêntica mas desta feita sem recurso ao peitoral naóforo. Neste caso as serpentes envolvem o amuleto do coração que, por sua vez, está preso a um colar de contas. Museu do Louvre (AF 9593).

(39) Museu Egípcio do Cairo, JE 29669 (CG 6028).

(40) Museu Egípcio do Cairo (CG 6233).

(41) As crenças funerárias da XXI dinastia revelam um grande entrosamento entre as crenças solares e as osiríacas. Ver NIWINSKY, op. cit., p. 15.

(42) Museu Egípcio do Cairo, JE 26197 (CG 61029C) e J.E. 26199 (CG 61030). Em ambos os casos, a representação foi colocada nos ataúdes exteriores.

(43) Em certos exemplares, o escaravelho foi representado com a cabeça de carneiro, o que, para Niwinski, constitui a imagem mais compacta do Ser supremo, constituindo uma forma criptográfica do nome Ré-Atum-Khepri, à qual se reunia o amuleto cordiforme como um simbolo de Osíris. Em NIWINSKI, "The solar-osirian unity as principle of the theology of the "State of Amun" in Thebes in the XXI dynasty", JEOL 30 (1987-1988), pp. 87-106.

(44) A visão de um deus supremo ficou marcada, no Império Novo, pela ideia de um deus solar, princípio de vida e causa última da criação, e de um deus ctónico, princípio de regeneração e de renascimento. Ambos os princípios são complementares e mutuamente dependentes. Em Idem, p. 89.

(45) Nesta perspectiva, o amuleto cordiforme surge prioritariamente como uma evocação osiriaca (sublinhada por vezes com a representação do totem tauer ou do próprio nome de Osíris, Wsir) que é frequentemente colocada em relação dinâmica com um símbolo solar (como o ba, o disco solar, a ave benu ou o escaravelho solar). Dois ciclos religiosos dominam o pensamento teológico do Império Novo: o do Sol (que simboliza o deus transcendente, elevado e visível) e o de Osíris (encarnando o imanente, a causa subterrânea da vida e o invisível). São perspectivas complementares e constituem uma unidade que se tornou ao longo do tempo cada vez mais indissociável, culminando, na XXI dinastia, na formulação de uma unidade completa entre Ré e Osíris. A rica iconografia deste período reflecte a unidade dos aspectos solares e ctónicos do grande deus. Na verdade, cada representação complexa de um símbolo deve ser entendida como tendo um simultaneamente sentido solar e ctónico. A imagem mais compacta do Ser supremo era expressa iconograficamente na figura do escaravelho encimado pela cabeça de carneiro à qual pode ser adicionado outros elementos como asas, falo, disco solar, ou coroas., Esta figura podia ser usada como forma criptográfica do nome Ré-Horakhti-Atum-Khepri. Em Idem, p. 91-102. Deste modo, as grandes representações de escaravelhos alados e de amuletos 
do coração que decoram magnificamente o peito dos ataúdes antropomórficos deste período, jogam intencionalmente com a dualidade do simbolismo inerente ao escaravelho do coração e ao amuleto cordiforme para extrair uma imagem que manifeste a síntese entre Osíris e Ré.

(46) Trata-se de uma característica comum nas representações elaboradas sobre os ataúdes da XXI dinastia. Frequentemente os motivos das constelações solares e ctónicas são combinadas no seio de uma mesma estrutura formal, como acontece nas representações sobre as quais agora nos debruçamos. É, portanto frequente que uma representação, aparentemente solar ou osiríaca, revele interpenetrações com motivos da constelação simbólica complementar. Sobre a iconografia representada nos ataúdes da XXI dinastia ver Idem, pp. 89-106.

(47) O sarcófago de Setueret é um dos mais belos exemplares deste período conservado no Museu Egípcio do Cairo (23/1/21/9).

(48) Ver IKRAM e DODSON, The Mummy in Ancient Egypt: Equipping the Dead for Eternity, The American University in Cairo Press, 1998, Cairo, pp. 238-239.

(49) Museu do Louvre, N 28676.

(50) É o caso do ataúde Irethoreru, conservado no Museu Britânico, n. 20045.

(51) Ver Idem, pp. 240-241.

(52) Museu Britânico, EA 9900/32.

(53) Tal é o caso da estela de Mesu e Api, encontrada em Deir el-Medina (hoje no Museu do Louvre, C 280).

(54) Ver MAYSTRE, Tombes de Deir el-Médineh: La tombe de Nebenmât (n. $\left.{ }^{\circ} 219\right)$, Colecção MIFAO, vol. 71, IFAO Cairo, 1936, pl. V.

(55) Ver TAYLOR, Death and the afterlife in ancient Egypt, British Museum Press, Londres, 2001, p. 20. Sobre Nesitanebtacheru ver ARAÚJO, op. cit, p. 896.

(56) Ver TAYLOR, op. cit., p. 231.

(57) Ver a título de exemplo a vinheta da psicostasia no "Livro dos Mortos" de Khonsumés, Kunsthistorisches Museum (N. Inv. AOS 3859).

(58) Apenas uma destas representações retrata uma mulher, Unet, uma cantora de Amon que comparece diante do tribunal de Osíris com um amuleto do coração. Museu do Louvre, AF 9593.

(59) Também aqui se detecta um uso do amuleto unicamente por parte do homem. Quando um casal é representado, é sempre o homem que ostenta o amuleto. Ver, por exemplo, a vinheta da adoração a Osíris do "Livro dos Mortos" de Kha e Merit, do Museu Egípcio de Turim. Em ROVERI, Museo Egizio, Barisone Editore, Turim, s/d, p. 32.

${ }^{(60)}$ Ver DAVIS, The Funeral Papyrus of louiya. With an Introduction by Édouard Naville, Archibald Constable and Co., Ltd., Londres, 1908, PI. I. Note-se que, no âmbito dos objectos encontrados no KV 46, já aqui fizemos referência a objectos que fazem alusão ao amuleto cordiforme: a estatueta funerária de luia, assim como um amuleto ambíguo que tanto pode ser classificado como um escaravelho do coração como um grande amuleto cordiforme. As representações patentes quer no "Livro dos Mortos" quer na estatueta funerária podem constituir uma alusão a um objecto que efectivamente existia e que pode ter sido o próprio amuleto/escaravelho do coração usado na múmia.

(61) Ver FRANKFORT, The Cenotaph of Seti I, II, pl. LXXIII. 
(62) Ver MALAISE, “La signification des pendentifs cordiformes dans l'art égyptien», Cd'É 50 (1975), p. 110.

(63) Idem, p. 113. Este jogo adquiriu conotações funerárias sobretudo a partir do Império Novo, sendo mencionado no capítulo 17 do "Livro dos Mortos". Simbolicamente o jogo fazia alusão à existência no Além, a qual era vista como uma partida jogada com as entidades que aí habitavam. O sucesso estava assim relacionado com uma existência feliz no outro mundo. Não esqueçamos que, na escrita hieroglífica, o jogo significa "perdurar", facto que poderá estar na base do simbolismo funerário que o jogo adquiriu. Ver WILKINSON, Reading Egyptian Art, Thames and Hudson, Londres, 1992, p. 211. Entre os vários jogos conhecidos o do senet terá sido, porventura, o mais popular (ver SOUSA, "Jogos", em L. Araújo (dir.), Dicionário do Antigo Egipto, pp. 458-459.

(64) Ver ataúde exterior de Pakharu, Museu Nacional de Alexandria (Proveniente do Museu Egípcio do Cairo: CG 6122/6121). Veja-se também NIWINSKY, Catalogue Général des Antiquités Égyptiennes du Musée du Caire, n. ${ }^{\circ}$ 6069-6082: The Second Find of Deir el-Bahri (Coffins), Supreme Council of Antiquities of Egypt, Institut of Archaeology of the Warsaw University \& Polish Centre of Mediterrean Archaeology in Cairo, Cairo, 1999, p. 56.

${ }^{(65)}$ Ver ataúde de Nesi, NIWINSKY, The Second Find of Deir el-Bahri (Coffins), p. 6.

(66) Ver NIWINSKY, Studies on the Illustrated Theban Funerary Papyri, p. 41.

(67) "Livro dos Mortos" de Hori, Cleveland Museum of Art (1921.1032). Ver BERMAN e BOHAC, Catalogue of Egyptian Art, Cleveland Museum of Art, 1999, p. 371.

(63) Ora este capítulo começa com a proclamação da vitória de Ré sobre os inimigos da luz (corporizados na tartaruga): "Que Ré viva e morra a tartaruga! O corpo está reunido sob a terra. Os ossos de Osíris N. estão (também) reunidos (...)". Capítulo 161 do "Livro dos Mortos". Ver BARGUET, Le Livre des Morts dês Anciens Égyptiens, Les Éditions du Cerf, Paris, 1967, p. 227.

(69) O fim do período ramséssida e a XXI dinastia constituem o auge do desenvolvimento da expressão pictórica do pensamento religioso do clero tebano. As composições iconográficas reflectem as concepções teológicas abstractas e ilustram um conhecimento iniciático de verdades e de mistérios que só podiam ser plenamente vividos no Além. NIWINSKI, "The solar-osirian unity as principle of the theology of the "State of Amun" in Thebes in the XXI dynasty", JEOL 30 (1987-1988), p. 91.

(70) Ver TAYLOR, Death and the Afterlife in ancient Egypt, p. 18.

(71) O testemunho proporcionado pela decoração tumular é especialmente importante, não só pelo significado explícito, mas também pelo significado implícito. $\mathrm{Na}$ verdade, inicialmente a decoração da câmara funerária parece ter sido uma prerrogativa real que gradualmente foi sendo alargada aos funcionários reais (Ver NIWINSKY, Studies on the lllustrated Theban Funerary Papyri of the 11th and 10th centuries B.C., p. 31). Durante a XVIII dinastia, o primeiro funcionário a merecer uma tal distinção foi Senmut. O caso de Sennefer testemunha, portanto, um privilégio excepcional no âmbito da XVIII dinastia.

(72) Ver Museu Egípcio do Cairo JE 32094 e JE 34417.

(73) A representação foi pintada sobre o pilar nordeste da câmara funerária de Sennefer.

(74) Ver DAVIES, Two Ramesside Tombs at Thebes, The Metropolitan Museum of Art, Nova Iorque, 1927, pl. XI.

(75) Ver SPIESER, "L'eau et la regeneration des morts d'après les représentations des tombes thébaines du Nouvel Empire», CdÉ 72 (1997), p. 224. 
(76) Ver FRANKFORT, The Cenotaph of Seti I, II, plate LXXIII.

(77) Museu do Louvre, E 3864.

(78) O Osireion de Abido, como vimos na primeira parte do nosso estudo, não era um edifício cultual comum. Era um complexo cenotáfio que reproduzia um complexo funerário tebano, constituído pelo templo funerário e o túmulo do Vale dos Reis. O cenotáfio propriamente dito é uma réplica dos túmulos tebanos no Vale dos Reis. A câmara funerária estava em ligação simbólica com a câmara que celebrava a regeneração do sol no seio de Nut. As representações do amuleto cordiforme localizam-se precisamente na passagem que dava acesso ao "ventre de Nut". As representações sugerem, deste modo, que o amuleto cordiforme estava relacionado com a possibilidade de efectuar a regeneração no ventre de Nut, ou seja, como refere o próprio Henry Frankfort, sugere um simbolismo relativo a um segundo nascimento no Além. Ver FRANKFORT, The cenotaph of Seti I at Abydos, p. 27. A constelação de símbolos que rodeia a purificação também contribui para intensificar as conotações relacionadas com a regeneração. Osíris, que apresenta a cornamenta característica de Tatenen, é um deus primordial. Diante do rei estão colocados o estandarte de Uepuauet, encimado por um cão selvagem, e o cheched, que representa a placenta real e que, muitas vezes, é encarada como o "duplo real». Ver WILKINSON, The Complete God and Goddesses of Ancient Egypt, American University in Cairo Press, Thames \& Hudson, Cairo, 2003, p. 192. O estandarte de Uepuauet era um elemento importante na celebração dos mistérios de Osíris em Abido. Com efeito, sabemos que o estandarte de Uepuauet liderava a procissão celebrada em Paker e aludia aos castigo dos inimigos e à retaliação do primogénito para vingar o seu pai e restabelecer a ordem. Em KAMAL, "The stela of $s$ htp ib $r^{r}$ in the Egyptian Museum", ASAE 38 (1938), p. 275. Todos estes elementos são indicativos de um novo nascimento.

(79) Ver GARDINER, “The Baptism of Pharaoh», JEA 36 (1950), pp. 3-12.

(80) Ver Museu do Louvre, N 1562.

(81) Ver Museu Egípcio de Berlim, N 728.

(82) Ver Museu do Louvre, E 25309. 